\title{
The urbanization impact in China: a prospective model (1992-2025)
}

\section{Blanca Arellano, Josep Roca}

Blanca Arellano, Josep Roca, "The urbanization impact in China: a prospective model (1992-2025)," Proc. SPIE 10767, Remote Sensing and Modeling of Ecosystems for Sustainability XV, 107670A (18 September 2018); doi: $10.1117 / 12.2321267$

SPIE Event: SPIE Optical Engineering + Applications, 2018, San Diego, California, United States 


\title{
The urbanization impact in China: A prospective model (1992-2025)
}

\author{
Blanca Arellano \\ UPC, Technical University of Catalonia, Barcelona, Spain \\ blanca.arellano@upc.edu \\ Josep Roca \\ UPC, Technical University of Catalonia, Barcelona, Spain \\ josep.roca@upc.edu
}

\begin{abstract}
The gradual spread of urbanization, the phenomenon known under the term urban sprawl, has become one of the paradigms that have characterized the urban development since the second half of the twentieth century and early twenty-first century. The arrival of electrification to nearly every corner of the planet is certainly the first and more meaningful indicator of artificialization of land. In this sense, the paper proposes a new methodology designed to identify the highly impacted landscapes in China based on the analysis of the satellite image of nighttime lights.

The night-lights have been used widespread in scientific contributions, from building human development indices, identifying megalopolis [2] [3] or analyzing the phenomenon of urbanization and sprawl [4], but generally they have not been used to forecast the urbanization in the near future. This paper proposes to study the urbanization impact in China between 1992 and 2013, and models a hypothesis of future scenarios of urbanization (2013-2025). For this purpose, the paper uses DMSP-OLS Nighttime Lights $(1992$ - 2013). After obtaining a homogeneous series for the whole period 19922013 , we proceed to model the spatial dynamics of past urbanization process using the "urbanistic potential" of each of the 13.7 millions of analyzed cells. This model allows to design a probable growth of the urbanization phenomenon between 2013 and 2025 as well to predict a progressive displacement of the urbanization from east coast to mainland and west, in congruence with the current demographic models [5].
\end{abstract}

Keywords: Night-time lights; Urbanization in China; Prospective Models; Urban Sprawl; Remote Sensing; Urban Areas.

\section{INTRODUCTION}

Since the mid-twentieth century there has been a true "explosion" of urbanization on a global scale. The urban population has grown from 750 million people in 1950 to 2,860 in 2000, more than 50\% of the world population [6]. In the Developed World, the urban model has suffered significant changes in recent decades, transforming from a model of urban continuum of medium and high densities to a model of an endless diffuse and sprawled city, driven by technological innovation processes, separation of functions and seeking proximity to nature [7]. In developing countries, the diffusion of urbanisation is even more pronounced. If in 1950 only 300 million inhabitants lived in cities, it is expected that in 2030 the 4000 million have been reached, representing $4 / 5$ of the world urban population [8]. Therefore, since 1950 there has been a real reversal in the topology of the landscape [9]. Landscapes that are highly artificialized have changed from "islands" within the "rural ocean" to "colonise" almost the entire planet. The process of urban sprawl has relegated to open spaces the role of auxiliary elements within the spatial structure. The sprawl in residential areas is linked to the gradual decentralisation of economic activity, first the industry, and then the services and even the most qualified tertiary activities. Urban sprawl, the massive consumption of land, can be found worldwide, although it takes many different forms in different regions and continents.

Remote Sensing and Modeling of Ecosystems for Sustainability XV, edited by Wei Gao,

Ni-Bin Chang, Jinnian Wang, Proc. of SPIE Vol. 10767, 107670A - C 2018 SPIE

CCC code: $0277-786 X / 18 / \$ 18 \cdot$ doi: $10.1117 / 12.2321267$

Proc. of SPIE Vol. 10767 107670A-1 
China has not been an exception. Since the early 90's, China has been undergoing an accelerated urbanization process [10] [11] Fang \& Yu, 2016. The built-up area in China increased from $7,438 \mathrm{~km}^{2}$ in 1981 to $32,520.7 \mathrm{~km}^{2}$ in 2005 , an increase of 3.37 times [12]. In that same period, the population grew by $32.98 \%$, from $993,877,310$ in 1980 to $1,321,623,490$ in 2005. The process of urbanization in China is, therefore, greatly accused.

Despite the extraordinary growth of cities in recent decades, there is no unanimous academic consensus about what "urbanisation" means. The plural nature of the forms of human settlement make it difficult to identify the urbanisation processes. This difficulty leads to an absence of any global database that would allow comparative studies of the urbanisation processes worldwide. An example of this difficulty lies in the ambiguous definition of urban and rural population of the UN. The diversity of criteria used by nations not allows reliable comparisons about the degree of urbanisation at international scale.

Unlike in the USA, where the Census Bureau precisely defines urban areas ${ }^{l}$, it seems that there is no one unified set of criteria to identify urban (and metropolitan) systems on a planetary scale. In Europe alone there seems to be a similar (although not identical) concept to that used in the USA to identify urbanized areas. Eurostat, that initially focused its efforts on delimiting Larger Urban Zones (LUZ), similar to the American metropolitan areas, has recently implemented a method that aims to define the Degree of Urbanisation Classification (DEGURBA) of Europe ${ }^{2}$.

The very concept of urbanisation is ambiguous. Urbanisation has traditionally been defined as "the process by which towns and cities are formed and become larger as more and more people begin living and working in central areas" (MerriamWebster Dictionary), "the process of creating towns in country areas" (Collins), "a population shift from rural to urban areas" (Wikipedia) or "the process by which large numbers of people become permanently concentrated in relatively small areas, forming cities" (Britannica). Nevertheless this definition does not completely fit the urbanisation processes initiated in the second half of the $20^{\text {th }}$ Century, when a significant part of the population had left traditional centers, seeking a greater proximity to natural spaces on the edges of the sprawl. This has led academics coming from the field of geography to speak of "counterurbanization" [17], "desurbanization" [18], "città difusa", or other similar terms, suggesting that the urbanisation processes would have come to an end (in the more developed world). Others, however, have spoken of the urbanisation of the countryside, or "rurbanization" [19], disseminating terms such as "rural sprawl" [20] or "ex urban sprawl" [21]. In this context, rather than speaking of the crisis of the urbanisation processes we must refer to the progressive disappearance of the city-country contradiction, in a context of extension of the urbanisation networks throughout the territory $[9,22]$.

There is a second concept of "urbanisation" that is less widespread than the first. A concept based on the idea of the physical transformation of the landscape, not on the conversion of "countryside" into "city". According to various dictionaries, urbanisation would be "the action and effect of urbanizing". In a similar way to building process, urbanisation would represent, from this second concept, the transformation of the primordial rural landscape by the incorporation of services networks characterized by a high artificialisation (vehicle access, paving, lighting and other public services, water supply, electricity supply, sewers, etc.). Nevertheless this second sense also incorporates a significant dose of ambiguity. Firstly because urbanisation does not always come before building. In the peripheries in developing countries the land is

\footnotetext{
${ }^{1}$ The US Census Bureau [13] defines an urban area as "(it) will comprise a densely settled core of census tracts and/or census blocks that meet minimum population density requirements, along with adjacent territory containing non-residential urban land uses as well as territory with low population density included to link outlying densely settled territory with the densely settled core. To qualify as an urban area, the territory identified according to criteria must encompass at least 2,500 people, at least 1,500 of which reside outside institutional group quarters. The Census Bureau identifies two types of urban areas: a) Urbanized Areas (UAs) of 50,000 or more people; b) Urban Clusters (UCs) of at least 2,500 and less than 50,000 people" [14]. For 2010 Census there were 3,573 UA in USA, with a population of $308,745,538$ inhabitants $(80.7 \%$ of total population).

${ }^{2}$ The Degree of Urbanisation (DEGURBA) is a classification that indicates the character of an area [15]. The latest update of the classification is based on 2011 population grid and the 2014 Local Administrative Units (LAU) boundaries. This classification was established by Eurostat in 2010 [16] and is based on the demographic density of the grid of $1 \mathrm{~km}^{2}$ of the European region. DEGURBA differentiates three degrees of urbanisation according to the density: a) High-density cluster or urban centre (contiguous grid cells of 1 $\mathrm{km}^{2}$ with a density of at least 1,500 inhabitants per $\mathrm{km}^{2}$ and a minimum population of 50,000; b) Urban clusters (clusters of contiguous grid cells of $1 \mathrm{~km}^{2}$ with a density of at least 300 inhabitants per $\mathrm{km}^{2}$ and a minimum population of 5,000; and c) Rural grid cells (Grid cells outside urban clusters).
} 
usually divided into "plots" first and then it is built on (occupying the land) and then the service networks arrive afterwards. But, above all, because urbanisation is not always a single, comprehensive act, but is more commonly a process (especially in the "Third World") in which the service networks (vehicle access and electricity, first), the water supply, sewerage and later paving are gradually added. In this regard it would be necessary to speak of the gradient or intensity of the urbanisation, more than an integrated or single event.

Remote sensing allows detailed analysis of the ground cover and, therefore, the identification of the landscapes highly artificialized by the urbanisation processes. Satellite images, such as Landsat with a spatial resolution of $30 \mathrm{~m} /$ pixels and a high spectral resolution, make it possible to identify the urbanized areas. Nevertheless, despite remote sensing technology enabling the uniform analysis of land cover on a worldwide scale, the complexity of the urbanizing phenomenon and the high cost of computing make it difficult to generate an integrated database on a world scale. Previous spatial resolution GLC datasets $(300 \mathrm{~m}-1 \mathrm{~km})$ did not provide sufficient spatial and thematic details of land activities. GLC datasets had been developed and released in the past few years, and a new GLC data product (GlobeLand30) shows changes produced in ten land cover types. These $30 \mathrm{~m}$ GLC datasets provide more details of land cover patterns, permit the detection of land cover change at the scale of most human land activities, and enable a better understanding of landscape heterogeneity, as well as increase the performance of modelling and simulations [23]. However, high-resolution remote sensing data requires a large amount of human and computational resources to extract one-time urban information for large geographic areas, such as China, suggesting the need for other approaches.

On the other hand, there is no single methodology to measure the phenomenon of urbanisation [24, 25]. The plural nature of forms of human settlement greatly limits the identification of the urbanized area. The forms of human settlements differ markedly all over the world. From the predominantly rural structures of Africa and part of Asia and South America to the immense world megalopolises. From the big cities of Mesoamerica and Mexico to the infinite peripheries of the sprawl in the United States and central Europe. From the città difusa of the Po Valley, to the compact Mediterranean cities. Linear cities, following axes of communication; grid-based cities, by way of new contemporary centurions; monocentric structures vs. polycentric urban systems.

But it is not only the plural nature of the developed landscapes on the planet that limits identification and classification using remote sensing techniques. The different interaction between the diverse types of land covers also hinders the task of delimiting urbanized spaces. Urban areas, for example, include large spaces that cannot be built upon, green areas and even open spaces. The pattern of urban development is usually characterized by fragmentation; "leap frog" that hinders the identification of urban areas by merely identifying buildings. The scattered nature of urbanisation represents, therefore, an intrinsic difficulty in the identification and delimitation of urban areas by means of remote sensing. This difficulty is increased if we consider that the pixels resulting from the satellite images usually present "confusion" as they are a combination of various real types of land covers [26], which has led to a great variety of techniques aimed at optimizing the classification of the ground cover.

In the absence of an integrated approach of how identify urban areas, this paper uses the information derived from nighttime lights to delineate the areas impacted by urbanisation. Following previous research on a global scale [4], this paper attempts to evaluate the urban growth of China between 1992 and 2013, as well as to elaborate a prospective model of the Chinese urban expansion until 2025. Obtaining accurate and timely information about the dynamics of urban expansion is crucial to clarify the driving forces of urbanization, to estimate its effects, and to promote an effective urbanization process in China [27].

\section{METHODOLOGY}

The study assumes that night-time lights satellite imagery provides valuable information for the identification of human landscapes, such as rural and urbanized areas. The "dark" landscapes are certainly related to rural settlements. The landscapes of light and darkness detect more clearly than traditional statistics based on the percentage of urban/rural forms of human settlement on the world population, with the advantage, in turn, of allow it to be studied on a subnational level, which is not possible when simply using official statistics. Concerning the "lit" landscapes, it clearly identifies areas of the world characterized by high human artificialisation. The electricity supply, along with the division of land into plots and 
the "lines" of the streets ${ }^{3}$, represent the first steps in the process of urbanisation. The almost universal access to electrical energy as well as the diverse intensity of its use makes the analysis of night-time images an exceptional tool for studying the urbanisation gradient on a world scale. In the case of China, access to electricity is almost universal. In 1992 it reached 90.54\%, reaching 100\% in 2014 (World Bank, World Development Indicators).

For more than forty years the U.S. Air Force Defense Meteorological Satellite Program (DMSP) Operational Linescan System (OLS) has been collecting global low light imaging data ${ }^{4}$. In 2011 NASA [28] and NOAA launched the Suomi National Polar Partnership (SNPP) satellite carrying the first Visible Infrared Imaging Radiometer Suite (VIIRS) instrument ${ }^{5}$. The VIIRS collects low light imaging data and has several improvements over the capabilities of the OLS [29]. There is a major difference in the pixel footprint between both sensors. The VIIRS day-night band is ten to fifteen times better than the OLS system at resolving the relatively dim lights of human settlements and reflected moonlight. Each pixel shows 742 meters (0.46 miles) across, compared to the 3-kilometre footprint (1.86 miles) of DMSP. Beyond the resolution, the sensor can detect dimmer light sources. And since the VIIRS measurements are fully calibrated, scientists now have the precision required to make quantitative measurements of clouds and other features. VIIRS DNB uses sixtyfour detector aggregation zones ( 32 on each side) to maintain at a constant 742 meters from nadir out to edge of scan (http://earthobservatory.nasa.gov/Features/IntotheBlack/).

\begin{tabular}{|c|c|c|c|c|c|c|}
\hline \multicolumn{7}{|c|}{ Average Visible, Stable Lights, \& Cloud Free Coverages } \\
\hline Year\Sat. & F10 & F12 & F14 & F15 & F16 & F18 \\
\hline 1992 & F101992 & $-\cdots \cdot-$ & $\ldots$ & $\cdots$ & $-\cdots \cdot$ & $\ldots$ \\
\hline 1993 & F101993 & $-\cdots-\cdot-$ & $-\cdots$ & $\ldots$ & $-\cdots$ & 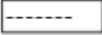 \\
\hline 1994 & F101994 & F121994 & $\ldots$ & $\cdots$ & $-\cdots \cdot$ & $\ldots$ \\
\hline 1995 & $\cdots$ & F121995 & 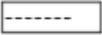 & $\ldots$ & $-\cdots$ & \begin{tabular}{|c|}
$-\cdots-.$. \\
\end{tabular} \\
\hline 1996 & $\ldots$ & F121996 & $\ldots$ & $\ldots$ & $-\cdots$ & 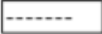 \\
\hline 1997 & $\ldots$ & F121997 & F141997 & $\ldots$ & \begin{tabular}{|c|}
$-\cdots-\cdot-$ \\
\end{tabular} & \begin{tabular}{|c|}
$-\cdots . .$. \\
\end{tabular} \\
\hline 1998 & $\mid-\cdots$ & F121998 & F141998 & ---o- & 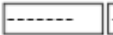 & \begin{tabular}{|l|}
$-\cdots-\cdots$ \\
\end{tabular} \\
\hline 1999 & $\mid \cdots . . .$. & F121999 & F141999 & $\cdots$ & $-\cdots \cdot$ & -....... \\
\hline 2000 & $-\ldots$ & 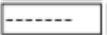 & F142000 & $F 152000$ & $-\cdots$ & 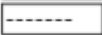 \\
\hline 2001 & $\ldots$ & $\ldots$ & F142001 & F152001 & $\ldots$ & $\ldots$ \\
\hline 2002 & -....... & -...... & F142002 & F152002 & -...... & -....... \\
\hline 2003 & - & \begin{tabular}{|l|}
$-\cdots-\cdot-$ \\
\end{tabular} & F142003 & F152003 & \begin{tabular}{|c|}
$-\cdots-\cdots$ \\
\end{tabular} & \begin{tabular}{|l|}
$-\cdots-\cdot$ \\
\end{tabular} \\
\hline 2004 & $\ldots$ & -....... & $\ldots$ & F152004 & F162004 & -...-... \\
\hline 2005 & -..... & \begin{tabular}{|l|}
$-\cdots-\cdot-$ \\
\end{tabular} & $-\cdots$ & F152005 & F162005 & \begin{tabular}{|c|}
$-\cdots-\cdot-$ \\
\end{tabular} \\
\hline 2006 & $\ldots$ & -.....- & $\ldots$ & F152006 & F162006 & -...... \\
\hline 2007 & $\ldots$ & 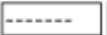 & $\ldots$ & F152007 & \begin{tabular}{|l|}
$F 162007$ \\
\end{tabular} & 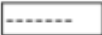 \\
\hline 2008 & $-\cdots$ & $-\cdots \cdots$ & $-\cdots+\cdots$ & $-\cdots+\cdots$ & F162008 & $-\cdots+\cdots$ \\
\hline 2009 & $\ldots$ & $-\cdots-\cdot$ & 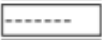 & $\cdots$ & F162009 & $\ldots-\cdots$ \\
\hline 2010 & - & \begin{tabular}{|l|}
$-\cdots-\cdot-$ \\
\end{tabular} & -..... & -..... & \begin{tabular}{|c|}
$-\cdots-\cdots$ \\
\end{tabular} & F182010 \\
\hline 2011 & $-\cdots$ & 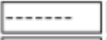 & 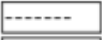 & $\ldots$ & $\ldots$ & F182011 \\
\hline 2012 & $\ldots$ & \begin{tabular}{|l|}
$-\cdots . .$. \\
\end{tabular} & -...... & $\ldots$ & - -..... & F182012 \\
\hline 2013 & $\ldots$ & -...-- & $-\ldots$ & $\ldots$ & $-\cdots$ & F182013 \\
\hline
\end{tabular}

Figure 1: Version 4 DMSP-OLS Nighttime Lights Time Series

\footnotetext{
${ }^{3}$ We understand here as "lined streets" the simple layout of the roads, as well as a slight compaction that allows the access to the parcels resulting from the division of rural property. Not the urbanization in an integral sense (pavement of the vials, construction of sidewalks, street lighting, ...).

${ }^{4}$ NOAA provides the DMSP-OLS databases on the website http://ngdc.noaa.gov/eog/dmsp/downloadV4composites.html (accessed on 1 November 2015). The files are cloud-free composites made using all the available archived DMSP-OLS smooth resolution data for calendar years. The products are 30 arc second grids, spanning -180 to 180 degrees longitude and -65 to 75 degrees latitude.

5 NOAA currently provides the SNPP-VIIRS data (version 1; January 2014 - March 2016) at the website http://ngdc.noaa.gov/eog/viirs/download_monthly.html (accessed on 8 August 2016). The Earth Observations Group (EOG) at NOAA/NGDC is producing a version 1 suite of monthly average radiance composite images using nighttime data from the Visible Infrared Imaging Radiometer Suite (VIIRS) Day/Night Band (DNB). This version 1 series of composites has not been filtered to screen out lights from aurora, fires, boats, and other temporary lights. This separation is under development and will be included in a later version of this time series. Version 1 spans the globe from $75 \mathrm{~N}$ latitude to $65 \mathrm{~S}$. The products are produced in 15 arc-second geographic grids.
} 
Despite the lower resolution and lack of calibration of OLS regarding VIIRS, only that sensor allows an extended dynamic analysis, as it is intended herein. The OLS sensor is suitable for detecting the dynamic process of urban expansion at a large spatial scale due to its appropriate spatial and temporal resolution [30]. DMSP-OLS nighttime light data have been demonstrated to be valuable for extracting information about urban expansion at global and national scales [31]. DMSPOLS nighttime light data have gradually become a preferred choice of source data to clarify the urban expansion process.

As we said, nighttime stable light (NSL) data, published by the National Geophysical Data Center (NGDC), enable good assessment of the dynamics of global urban expansion. However, six satellites were used to produce NSL data from 1992 to 2013, and OLS sensors have no on-board calibration. Furthermore, for each year, NSL the data acquired by different satellites do not have precise intercalibration. Without on-board calibration and intercalibration, NSL data include a large number of unstable lit pixels [30]. It is necessary to previously calibrate these aspects (on-board calibration and intercalibration) to proceed to a rigorous analysis of the urbanization process.

On the other side, given the absence of an international standard adopted to identify urban areas, the definition given by the US Census Bureau has been used. The urban areas obtained in this study therefore include noncontiguous territory separated by exempted territory (like bodies of water), via hops and jumps (maximum hop distance 0.5 miles, maximum jump distance 2.5 miles, and no hops after jumps) as well as other "natural" spaces highly impacted by urbanisation [13].

The methodology used in this paper can be summarized in the following steps:

1. First of all, the intercalibration of the nighttime lights derived for the years studied is carried out. In the absence of a unanimously accepted methodology to correct the lack of calibration of DMSP-OLS, the criterion used in this paper has consisted, first of all, in the modeling of night lights according to various variables (population, GDP, urban population,...). These models allow to evaluate the intensity of the night lights for the whole of China, overcoming the instability of the individual results of the data obtained from each of the satellites that have happened between 1992 and 20136.

2. The results obtained through the previous models have been applied to the years 1992-1995-2000-2005-20102013 through the redistribution of the totality of light predicted in the models according to the probability of each specific pixel. Said redistribution has been adjusted considering the maximum limit of the light intensity in each pixel (63, in the range 0-63). For the years when there were two satellites, the average probability between the two has been used. This has made it possible to partially correct the instability of the lit pixels obtained from the various sensors.

3. In order to determine the cut-off between urban and rural areas, this paper uses the methodology suggested by Arellano and Roca [4] to adjust a model for urban areas defined by the Bureau of Census in the USA. Transformation of night-time lights imagery into a point file allows a logistic regression to be performed with the 2010 US Urban Areas (UA) as a dependent variable, and night-time light intensity as an explanatory variable. This cut-off has been used to delimit Chinese urban areas between 1992 and 2013, as well as to assess urban growth in the same period.

4. Finally, a prospective model is carried out in order to determine the hypothetical urban growth between 2013 and 2025. For this, a model of urban potential is implemented, estimating the probability of urban development of each of the pixels illuminated in the previous period 2005-2013. The adjustment of the model by provinces allows to establish different hypothesis of growth in the mentioned period.

\footnotetext{
${ }^{6}$ The specialized literature has highlighted the difficulty of calibrating the information obtained through the DMSP-OLS sensors. The method suggested worldwide by Elvidge [31], to calibrate the data from a place that has not undergone major changes in its intensity and distribution of night light in time, does not seem to be applicable in China. Even the city of Jixi, used in some works [30] for the stability of its lights, has undergone major changes since 2008. All the above suggests the need to "calibrate" the data independently by using external indicators, such as population or the GDP.
} 


\section{RESULTS OF THE ANALYSIS}

\subsection{Intercalibration}

The analysis of the total light intensity of China obtained from the DMSP-OLS sensors shows a marked instability (figure 2 , table 1). The lack of "on board" and inter calibration of the various sensors is, as has been said, the main cause of this instability. It is necessary, therefore, to try to correct the data resulting from the successive satellites in order to determine, with a high degree of reliability, the urban development produced in China between 1992 and 2013.

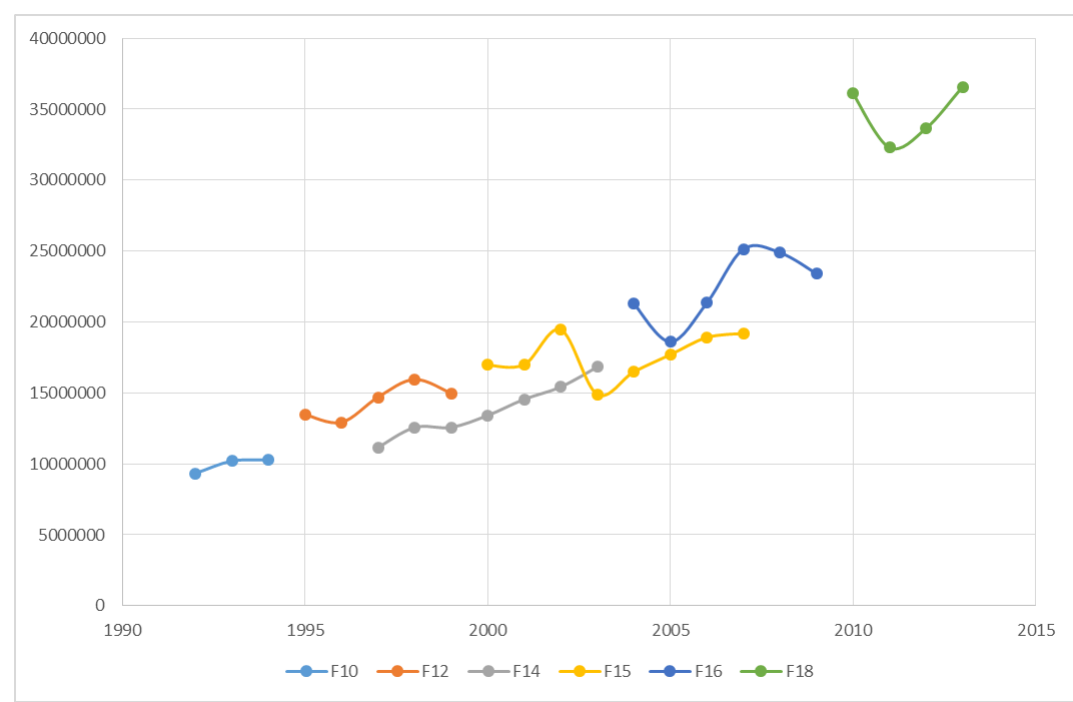

Figure 2. Sum of nighttime lights 1992-2013

\begin{tabular}{|c|c|c|c|c|c|c|}
\hline Year & F10 & F12 & F14 & F15 & F16 & F18 \\
\hline 1992 & 9336259 & & & & & \\
\hline 1993 & 10205794 & & & & & \\
\hline 1994 & 10275657 & & & & & \\
\hline 1995 & & 13491709 & & & & \\
\hline 1996 & & 12932475 & & & & \\
\hline 1997 & & 14703181 & 11151938 & & & \\
\hline 1998 & & 15959285 & 12571960 & & & \\
\hline 1999 & & 14974016 & 12577829 & & & \\
\hline 2000 & & & 13414628 & 16971756 & & \\
\hline 2001 & & & 14554041 & 16997632 & & \\
\hline 2002 & & & 15425755 & 19459714 & & \\
\hline 2003 & & & 16828932 & 14906120 & & \\
\hline 2004 & & & & 16482307 & 21318729 & \\
\hline 2005 & & & & 17694989 & 18606036 & \\
\hline 2006 & & & & 18909942 & 21339605 & \\
\hline 2007 & & & & 19198633 & 25135743 & \\
\hline 2008 & & & & & 24892561 & \\
\hline 2009 & & & & & 23409586 & \\
\hline 2010 & & & & & & 36118099 \\
\hline 2011 & & & & & & 32296214 \\
\hline 2012 & & & & & & 33642811 \\
\hline 2013 & & & & & & 36576457 \\
\hline
\end{tabular}

Table 1. Sum of nighttime lights 1992-2013 
In order to correct the lack of stability in the data obtained by the different satellites over time and ensure their intercalibration, a set of OLS models with different development indicators have been developed. Table 2 shows the correlations between the sum of night lights obtained from the DMSP-OLS sensors and the population, the percentage of urban oblation and the GDP per capita (constant US \$, 2010) in the period 1992-2013. It highlights the good performance of GDP pc $(\mathrm{R}=0.953)$, much better than the population $(\mathrm{R}=0.849)$, and even the percentage of urban population $(\mathrm{R}=$ 0.916).

\begin{tabular}{|ll|r|r|r|r|}
\hline & & Lights & GDP_pc & urban_percent & \multicolumn{1}{c|}{ Pop } \\
\hline Lights & Pearson Corr. & 1 &, $953^{\prime \prime}$ &, $916^{\prime \prime}$ & \multicolumn{1}{c|}{, $849^{\prime \prime}$} \\
& Sig & &, 000 &, 000 &, 000 \\
& $\mathrm{~N}$ & 33 & 33 & 33 & 33 \\
\hline GDP_pc & Pearson Corr. &, $953^{\prime \prime \prime}$ & 1 &, $975^{\prime \prime \prime}$ &, $906^{\prime \prime \prime}$ \\
& Sig &, 000 & &, 000 &, 000 \\
& $\mathrm{~N}$ & 33 & 33 & 33 & 33 \\
\hline urban_percent & Pearson Corr. &, $916^{\prime \prime}$ &, $975^{\prime \prime \prime}$ & 1 &, $974^{\prime \prime \prime}$ \\
& Sig &, 000 &, 000 & &, 000 \\
& $\mathrm{~N}$ & 33 & 33 & 33 & 33 \\
\hline Pop & Pearson Corr. &, $849^{\prime \prime}$ &, $906^{\prime \prime \prime}$ &, $974^{\prime \prime \prime}$ & 1 \\
& Sig &, 000 &, 000 &, 000 & \\
& $\mathrm{~N}$ & 33 & 33 & 33 & 33 \\
\hline
\end{tabular}

**. Corr. sign. 0.01 percent

Table 2. Correlations

The adjustment of the OLS model, therefore, will be made according to GDP pc (figure and table 3, cubic model). The high $\mathrm{R}^{2}$, confirms the good performance of the obtained model $\left(\mathrm{R}^{2}=0.913\right)$.

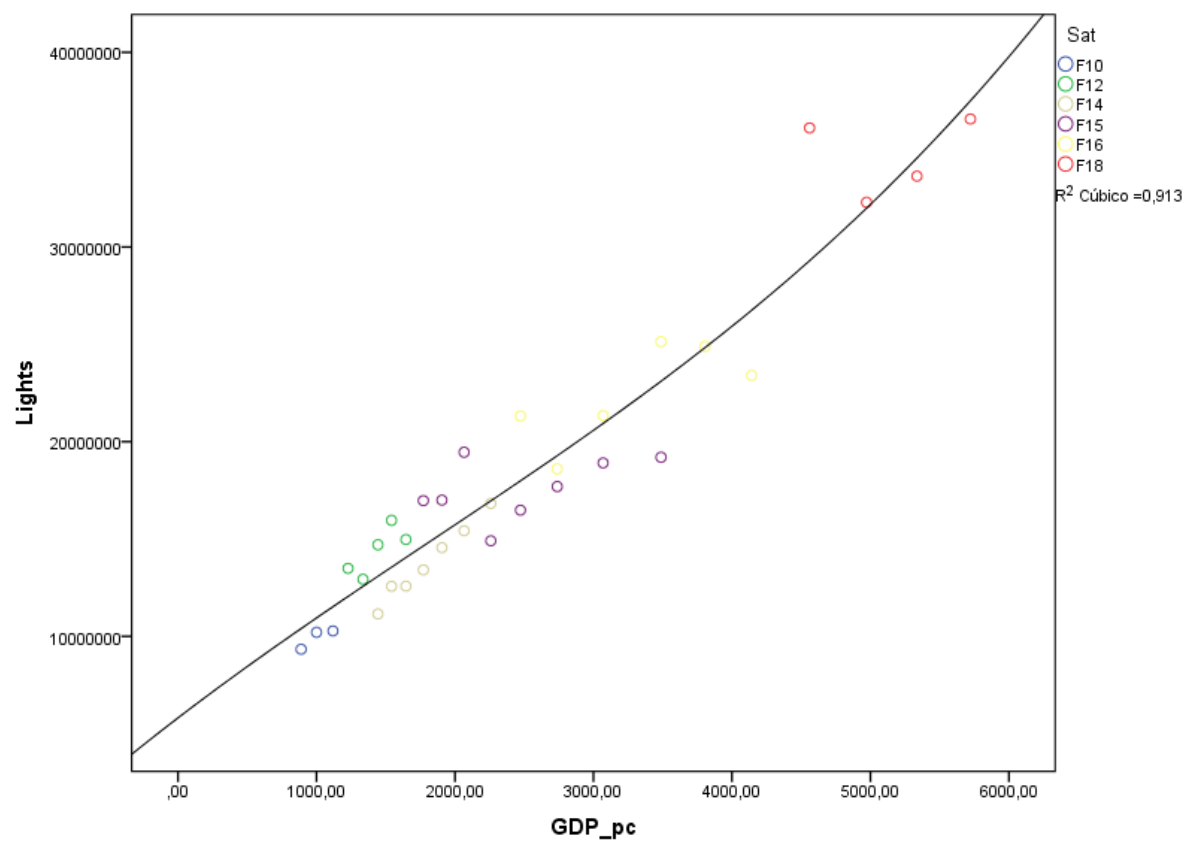

Figure 3. Cubic Model

Model
Dependent Variable: Lights
\begin{tabular}{|l|c|c|c|c|c|c|c|c|c|}
\hline \multirow{3}{*}{ Equation } & \multicolumn{9}{|c|}{ Model Summary } \\
\cline { 2 - 10 } & R 2 & F & gl 1 & gl 2 & Sig. & Constant & b1 & b2 & b3 \\
\hline Cubic & 913 & 101,095 & 3 & 29 &, 000 & 5812194,6 & 5449,087 &,- 385 & $7,015 \mathrm{E}-5$ \\
\hline
\end{tabular}
The independent variable is GDP_pc.

Table 3. Cubic model 
While the total Chinese population has experienced a growth of $16.52 \%$ and the percentage of urban population has gone from $28.2 \%$ in 1992 to $53.17 \%$ in 2013, the sum of (inter-calibrated) night lights has grown by $260.69 \%$. This demonstrates the vitality of urban expansion in China, which will be analyzed in the following epigraphs

\subsection{Urban Areas of China (1992-2013)}

The application of the OLS model for the years under study (1992, 1995, 2000, 2005, 2010 and 2013) allows a detailed analysis of inter-calibrated nighttime lights in China. Figure 4 shows the dynamics of the inter-calibrated night lights in the analyzed period. These images, however, do not yet allow a detailed analysis of the evolution of the urbanization process in China. Part of the night lights correspond to rurban spaces, not fully urbanized. We must therefore try to differentiate urban from rural areas.

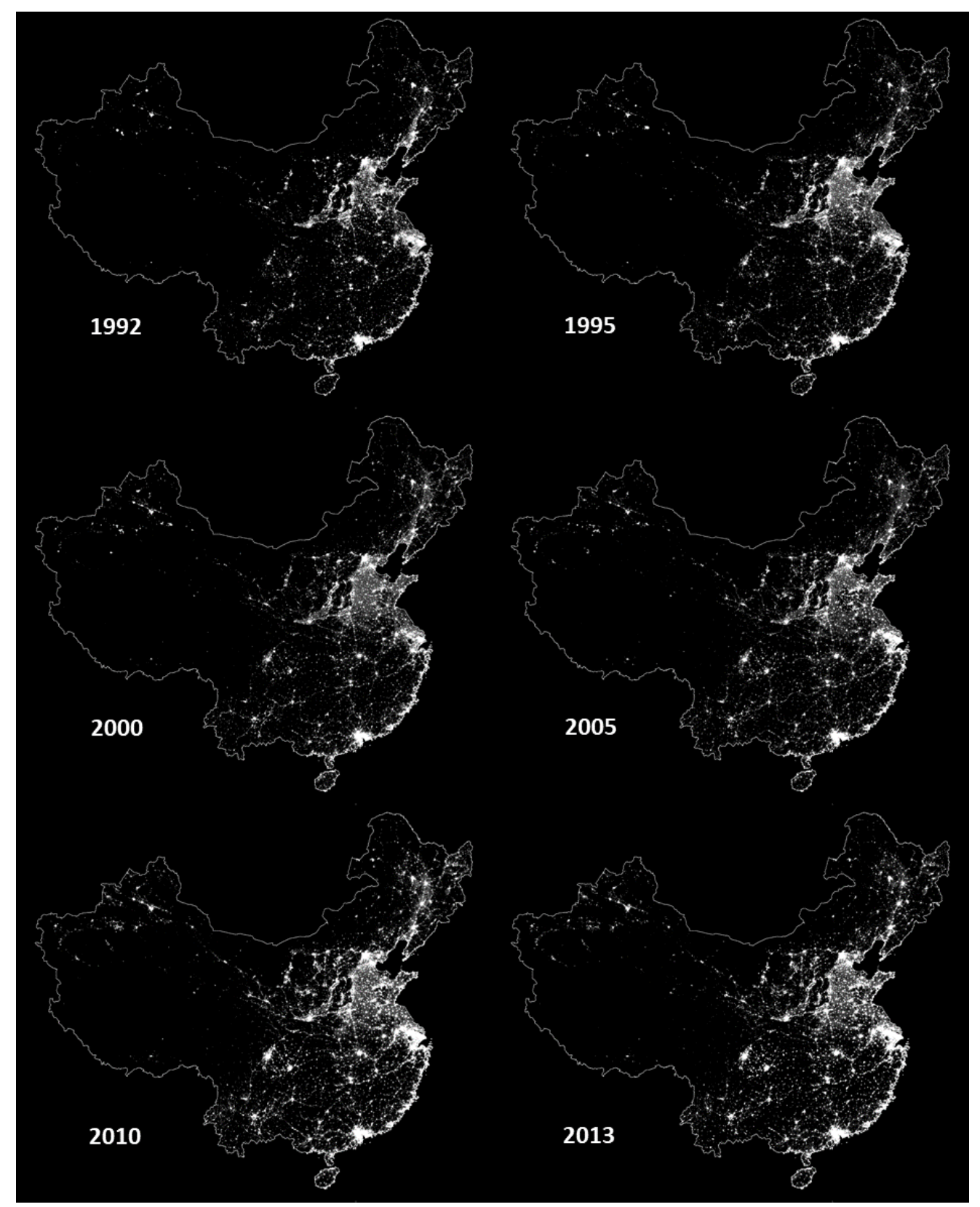

Figure 4. Inter-calibrated nighttime lights in China. 1992-2013 
As previously indicated, the methodology suggested by Arellano and Roca [4] will be used to delimit urban areas, as defined by the US Bureau of the Census. Transformation of nighttime lights DMSP-OLS imagery into a point file allows a logistic regression to be performed with the 2010 US Urban Areas (UA) as a dependent variable, and night-time light intensity as an explanatory variable. The logistic regression, adjusted for 15.8 million points $(2.6 \%$ of which correspond to UA), allows us to establish a night light intensity level of 37 (in a greyscale from zero to 63 levels of intensity) for the determination of those areas highly impacted by light. The results of this model can be seen in Table 4 . The model has an effectiveness level of $86.6 \%$ to explain the UA pattern in US. Figure 5 shows the result of the model for the UA in Southern California (red contour $=\mathrm{UA}$; white polygon $>=37$ intensity level contour) ${ }^{7}$.

\begin{tabular}{|c|c|c|c|}
\hline \multicolumn{4}{|c|}{ Resumen del modelo } \\
\hline Paso & $\begin{array}{l}-2 \log \text { de la } \\
\text { verosimilitud }\end{array}$ & $\begin{array}{c}\text { R cuadrado } \\
\text { de Coxy Snell }\end{array}$ & $\begin{array}{l}\text { R cuadrado } \\
\text { de } \\
\text { Nagelkerke }\end{array}$ \\
\hline 1 & $460612,815^{a}$ & .194 & .892 \\
\hline
\end{tabular}

\begin{tabular}{|c|c|c|c|c|c|c|c|}
\hline \multicolumn{8}{|c|}{ Variables en la ecuación } \\
\hline & & B & E.T. & Wald & gl & Sig. & $\operatorname{Exp}(\mathrm{B})$ \\
\hline \multirow[t]{2}{*}{ Paso $1^{a}$} & OLS13 & .246 & .000 & 364938,389 & 1 & .000 & 1,279 \\
\hline & Constante & $-8,921$ & .013 & 484189,998 & 1 & .000 & .000 \\
\hline
\end{tabular}

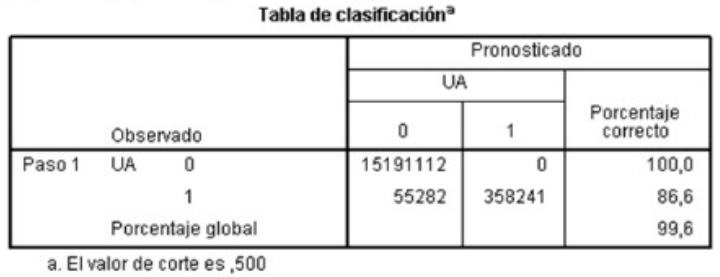

Table 4. Logistic regression US Urban Areas

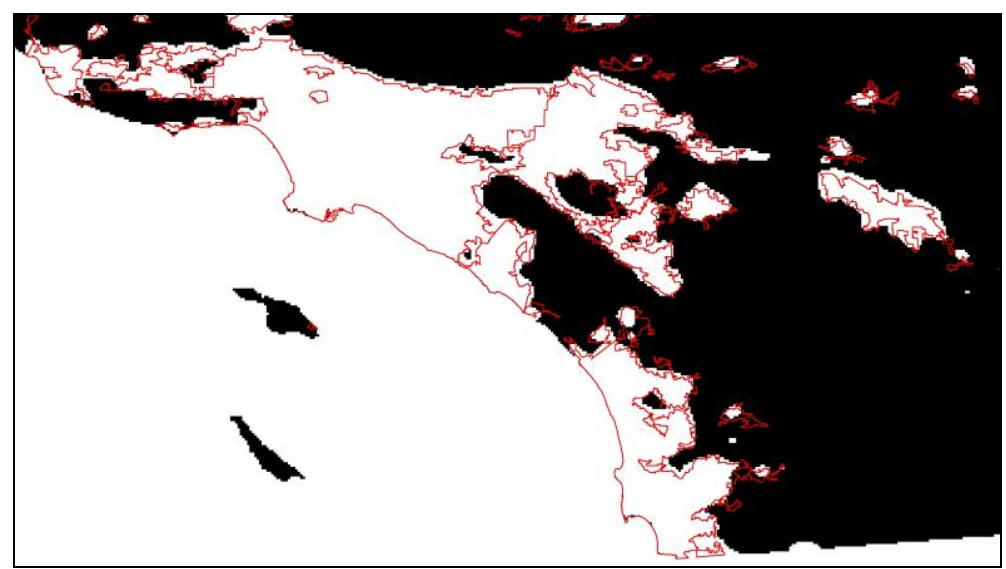

Figure 5. Highly light Impacted (intensity => 37) and Urban Areas in Southern California

This cut-off ( $>=37$ ) has been used to define the UA of $1992^{8}$ and 2013. The analysis of the nocturnal lights allows to evaluate the urbanization process in China between 1992 and 2013. The increase of the urban areas in this period has been spectacular. The $21,525 \mathrm{~km}^{2}$ occupied by the urbanization in 1992 became $194,362 \mathrm{~km}^{2}$ in 2013 , which represents an increase of $803 \%$ !! The sprawl process is especially significant if one considers that in that same period the urban

\footnotetext{
${ }^{7}$ The logistic regression model is performed interactively, through successive iterations. The first iteration gives a cut-off of intensity 48 (out of 63), explaining $74.4 \%$ of the pixels in urbanized areas, as well as $99.4 \%$ of those located in rural areas. The model converges in the 6th iteration, with $86.6 \%$ of hits over the urbanized pixels in intensity 37 or higher.

${ }^{8}$ It is doubtful that the cut-off 37 is used to define the Chinese UA of 1992, since it responds to data of intensity of night light of 20102013. A more rigorous exercise should refer to the AU of 1990-1992. For reasons of economy, this paper is limited to using the 20102013 cut-off.
} 
population increased, according to the World Bank, from 328,521,540 to 721,691,798 inhabitants, $119.68 \%$ more ${ }^{9}$. Figure n. 6 presents the urban areas of China (1992-2013).

In $1990^{10}$ only 6 urban areas exceeded 3 million inhabitants. The first, the agglomeration of Guangzhou with 13,585,280 inhabitants. The second Shanghai, with a population of 6,515,326 inhabitants. The third, Beijing (5,447,699 inhabitants), followed by Hubei (3,545,201 inhabitants), Shenyang (3,162,793 inhabitants) and Chongqing (3,074,305 inhabitants).

In $2015^{11}, 10$ UAs exceeded 7 million inhabitants. The first of these, the conglomerate around Shanghai $(61,181,622)$ inhabitants and an area impacted by $\left.19,596.54 \mathrm{~km}^{2}\right)$, followed by the Pearl River agglomeration $(50,327,375$ inhabitants and an area of 14,290.82 $\left.\mathrm{km}^{2}\right)$, Beijing $\left(21,330,159\right.$ inhabitants and 4,236.69 $\left.\mathrm{km}^{2}\right)$, Tianjin $(10,800,736$ inhabitants and $\left.3,038.48 \mathrm{~km}^{2}\right)$, Chengdu $\left(10,455,884\right.$ inhabitants, 2,233.53 $\left.\mathrm{km}^{2}\right)$, Hangzhou $(10,158,031$ inhabitants and 3,535.06 km²), Wuhan (8,325,974 inhabitants, 3,324.72 $\mathrm{km}^{2}$, Quanzhou-Xiamen-Zhangzhou (7,933,873 inhabitants, 3,324.72 $\left.\mathrm{km}^{2}\right)$, Shenyang (7,146,431 inhabitants, 1,722.33 $\left.\mathrm{km}^{2}\right)$,) and Xi' an (7,063,560 inhabitants, 1,802.37 $\left.\mathrm{km}^{2}\right)$.

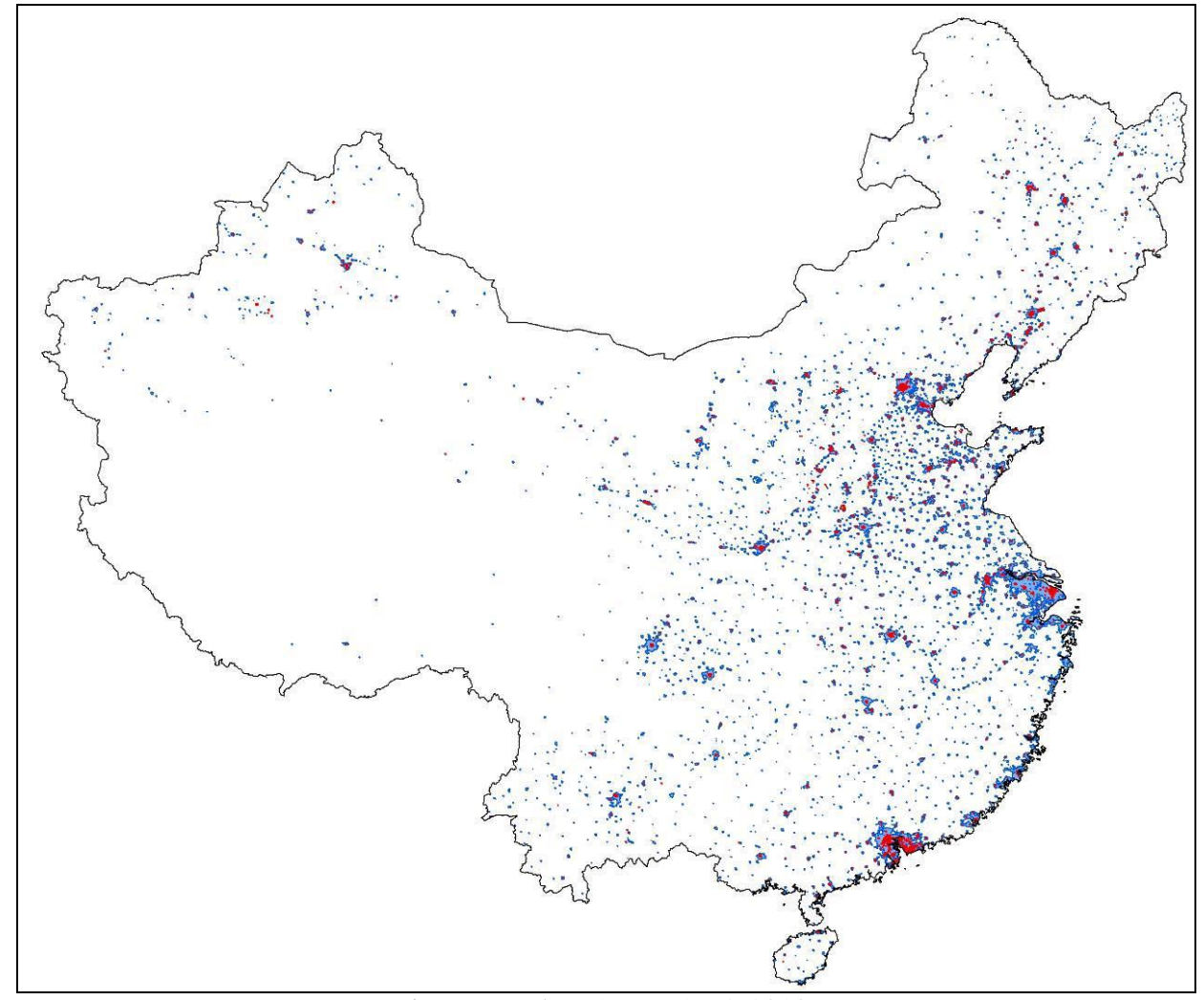

Figure 6. Urban Areas (1992-2013)

In general, the most urbanized provinces (Beijing, Shanghai, Tianjin and Guangdong) have experienced the least growth in urbanization between 1992 and 2013. Conversely, the least urbanized ones have seen greater growth. Figure 7 presents the results of the evolution of the night lights between 1992 and 2013. In dark green, the provinces with an increase in soil impacted by nightlight less than $300 \%$. In green color, those with a growth between 300 and $400 \%$. In yellow, the provinces

\footnotetext{
${ }^{9}$ If the population of the UAs defined in this study is considered, the evolution of the population between 1990 (referring to the urban areas of 1992) and 2015 (referred to the urban areas of 2013) would have grown by $324 \%$, from $144,161,492(1990)$ to $611,717,818$ (2015).

10 GHS population grid, derived from GPW4, 1990. European Commission, Joint Research Centre (JRC) [Dataset] PID: http://data.europa.eu/89h/jrc-ghsl-ghs_pop_gpw4_globe_r2015a.

11 GHS population grid, derived from GPW4, 2015. European Commission, Joint Research Centre (JRC) [Dataset] PID: http://data.europa.eu/89h/jrc-ghsl-ghs_pop_gpw4_globe_r2015a.
} 
with an increase in soil impacted between 400 and 500\%. And in red the provinces that have experienced an increase in land impact lights, higher than 500\%.

These results confirm the growing trend, revealed by recent work [5], towards the impulse of migratory movements towards central and western China. At present, a bi-directionality in the migratory movement would be taking place: next to the main trend, directed towards the East, an incipient movement towards the West would be configuring a new territorial structure in China. Mainland and Western China would represent the new emerging territories. Trend that is confirmed with the evolution of the centers of gravity of night lights, which moves slightly to the west and south of the country (figure 7). Figure 8 shows, by provinces, the increase in nighttime lights between 1992 and 2013 with respect to their average intensity in 1992. It can be seen how the provinces least urbanized in 1992 were those that experienced the most marked urbanization growth between that year and 2013.

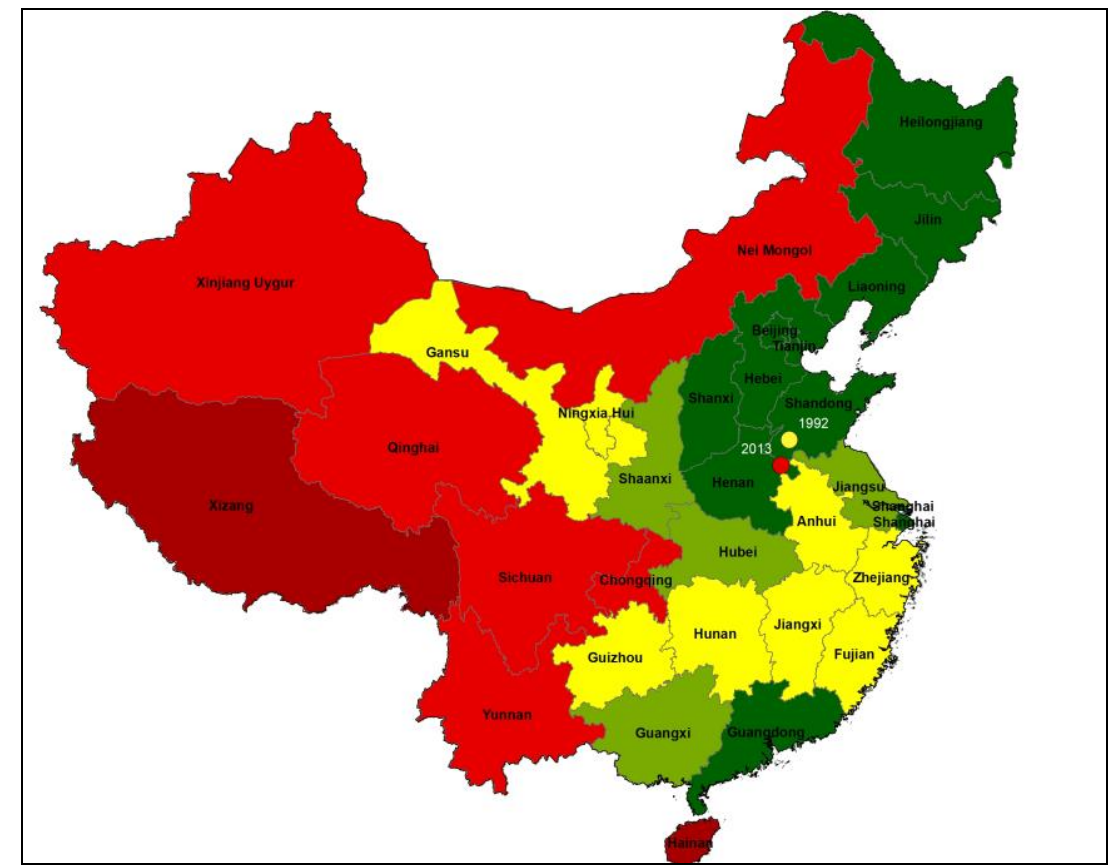

Figure 7. Increase in land impacted by light between 1992 and 2013

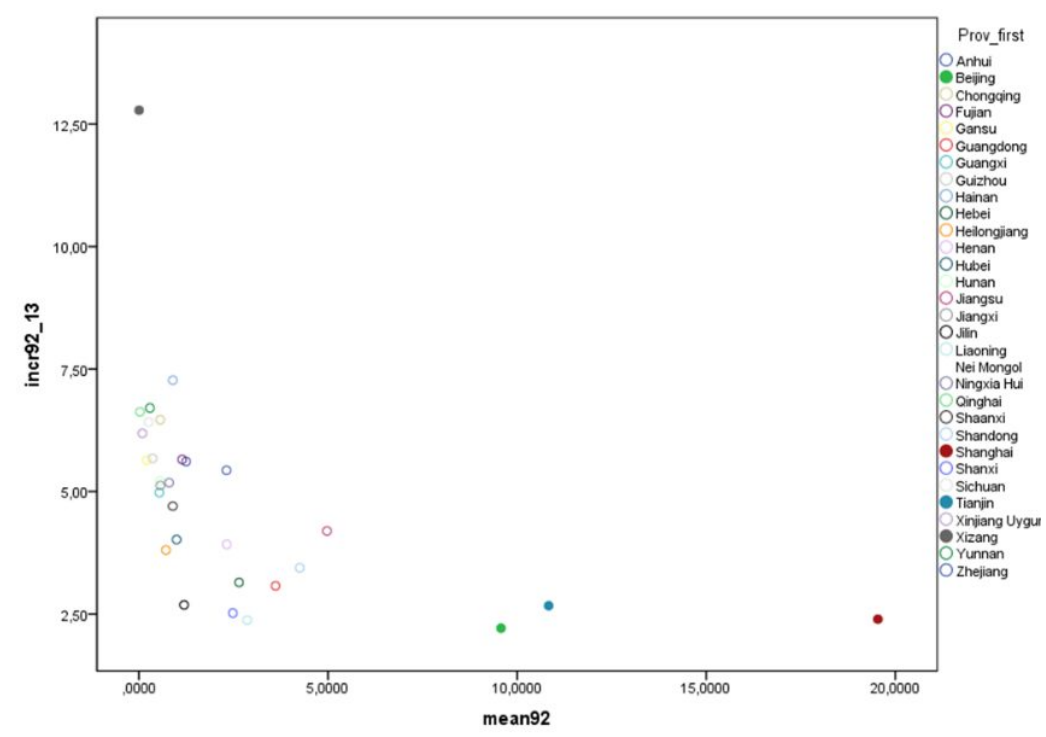

Figure 8. 
The study made it possible to know the urban dynamics of the different UAs between 1992 and 2013. As an example, the evolution of the three major Chinese urban agglomerations are presented below: Shanghai, Pearl River Delta, and BeijingTianjin.

- It stands out, above all the urban areas of China, the megalopolis conformed by the agglomerations of ShanghaiNanjing (61,008,537 inhabitants), Hangzhou (10,129,751 inhabitants) and other 61 UAs of more than 20,000 inhabitants (figure 9a). This megalopolis, delimited according to DMSP-OLS 2013 and referred to the population of GHS Population Grid $^{12}$, has a population of more than 93 million inhabitants and extends over an area impacted by the urbanization of 32,900 $\mathrm{km}^{2}$. In 1990 (GHS Pop Grid) the previous urban conglomerate of UAs (1992) almost reached the 19 million inhabitants, with an extension of land highly impacted by the light of $2,700 \mathrm{~km}^{2}$. The area studied has had a considerable sprawl, as evidenced by the fact that the artificial area has grown 1.45 times more than the population (table 5) ${ }^{13}$.

- In front of the previous megalopolis, the megalopolis conformed in the Delta of the Pearl River (figure 9b) seems small. This megalopolis includes, in addition to the main agglomeration structured around Guangzhou, Dongguan and Shenzhen (50,930,326 inhabitants 2015), other 14 UAs of more than 20,000 inhabitants (Hong Kong and Macao not included). It had in 2015 (GHS Population Grid) more than 55 million inhabitants and extended (2013) over 16,500 $\mathrm{km}^{2}$. In 1990, the megalopolis of the Pearl River Delta exceeded 18 million inhabitants (GHS Pop Grid), with an area of land highly impacted by the light (1992) of 4,200 $\mathrm{km}^{2}$. The increase of the area impacted by the urbanization has been much smaller than in Shanghai, 298\%. Even so, the urban sprawl of the Pearl River megalopolis is shown by the greater growth of the surface impacted by light with respect to the population (205\%).

- Finally, the third great Chinese urban structure is the megalopolis articulated around Beijing (21,342,276 inhabitants 2015) and Tianjin (10,816,731 inhabitants, 2015), along with other 41 UAs of more than 20,000 inhabitants. This megalopolis (figure 9c) groups more than 41 million inhabitants (2015, GHS Population Grid) and extends over about $11,000 \mathrm{~km}^{2}$ impacted by the urbanization. The agglomeration of UAs around BeijingTianjin reached, in 1990 and referred to the night lights of 1992, a total of 11,443,764 inhabitants and 1,983 $\mathrm{km}^{2}$ impacted by the night light. As can be seen in Table 5, the megalopolis of Beijing-Tianjin is the one that has experienced a more marked urban sprawl process in the period 1992-2013, as the land impacted by light grew 1.78 times more than the population.

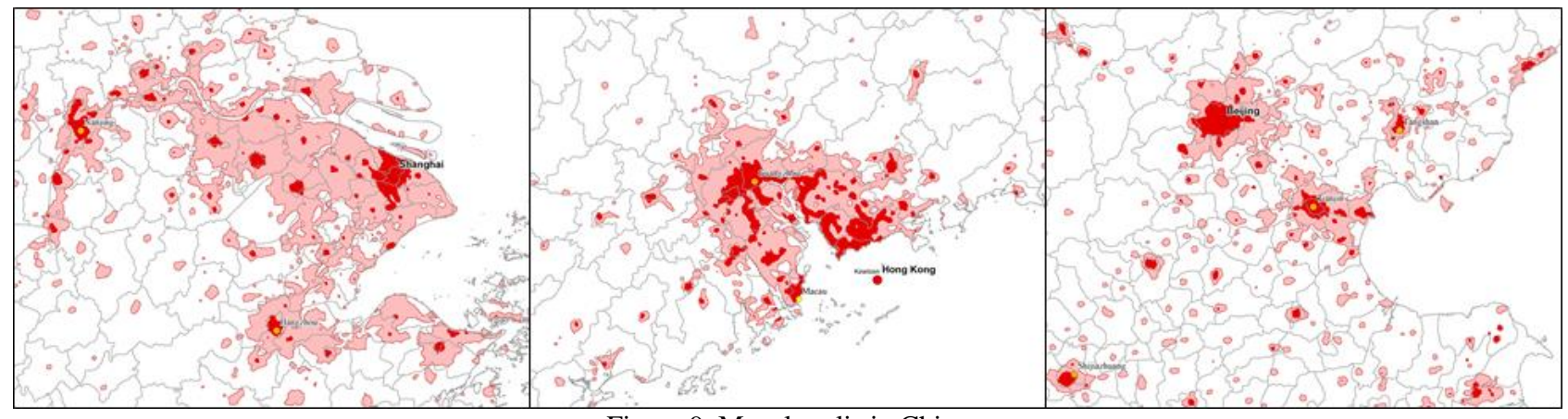

Figure 9. Megalopolis in China

\footnotetext{
${ }^{12}$ European Commission, Joint Research Centre (JRC); Columbia University, Center for International Earth Science Information Network - CIESIN (2015): GHS population grid, derived from GPW4, multitemporal (1975, 1990, 2000, 2015). European Commission, Joint Research Centre (JRC) [Dataset] PID: http://data.europa.eu/89h/jrc-ghsl-ghs_pop_gpw4_globe_r2015a.

13 The Shanghai UAs 2013 had, in 1990, a population of 56,050,225 inhabitants, with respect to the 18,925,642 inhabitants of the UAs of 1992. This marked difference is due (regardless of the errors that may exist in the application of a single cut-off to define the UAs of 1992 and 2013) to the existence of a high rural population (rurban population) in the vicinity of urban centers. The urbanization of these nuclei of rurban population has represented the explosion of sprawl in Shanghai and others metropolitan areas in China. The concept of rurban population can be analyzed in Arellano \& Roca 2017 [4].
} 


\begin{tabular}{|c|c|c|c|c|c|c|c|c|c|}
\hline Metro Area & Uas 92 & Pop 90 & Area 92 & Uas 13 & Pop 15 & Area 13 & Inc. Pop & Inc. Area & Ratio \\
\hline Shanghai & 76 & 18925642 & 2712 & 154 & 93161216 & 19597 & $392,25 \%$ & $622,67 \%$ & 1,59 \\
\hline Pearl River Delta & 57 & 18087203 & 4196 & 43 & 55231989 & 16707 & $205,37 \%$ & $298,20 \%$ & 1,45 \\
\hline Beijing & 39 & 11443764 & 1983 & 79 & 41247471 & 11188 & $260,44 \%$ & $464,24 \%$ & 1,78 \\
\hline
\end{tabular}

Table 5. Urban growth indicators 1990-92 / 2013-2015

\subsection{Prospective model (2013-2025)}

Finally, this paper has developed a prospective model for the period 2013-2025. A model based on the urbanistic potential of each pixel obtained from its specific location as well as the evolution of its degree of light intensity observed in the period 1992-2013.

The evolution of GDP per capita over the period 1992-2017 suggests that China will probably continue to see economic growth above the world average in the next 8 years, progressively bringing its level of development closer to that of the developed countries. Figure 10 shows the evolution of GDP per capita (constant 2010 US \$) between China and the United States.

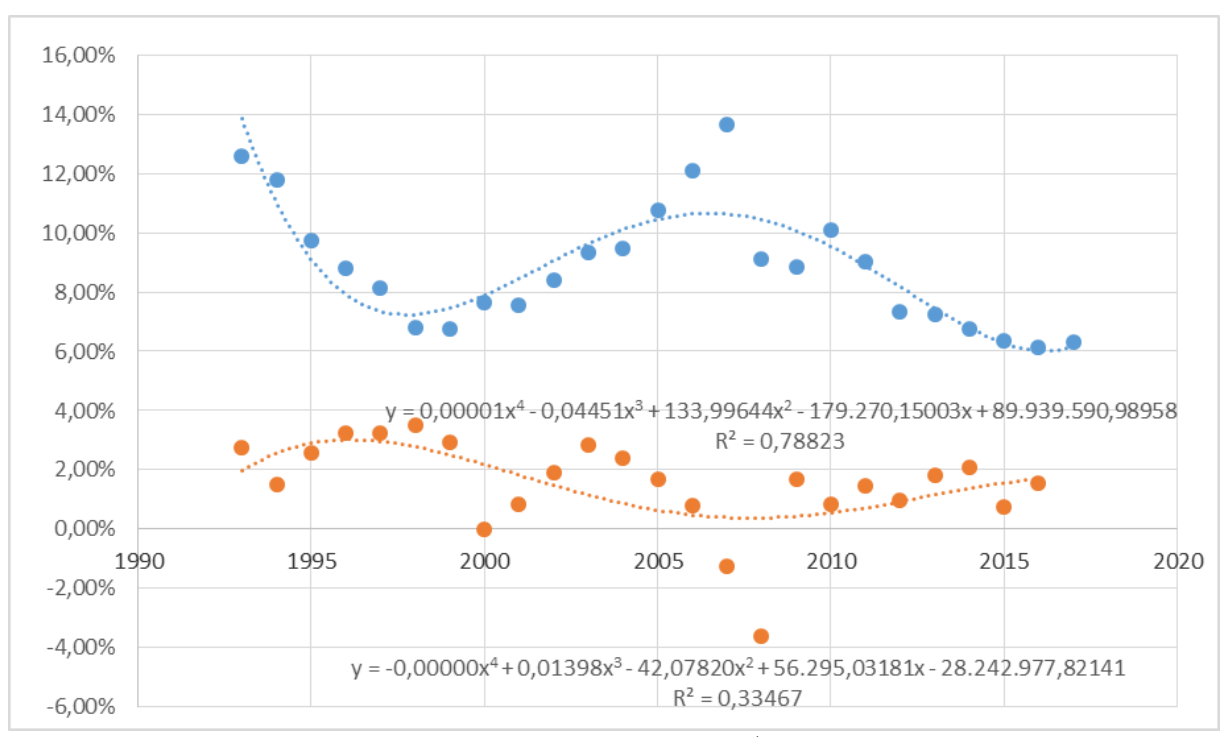

Figure 10. GDP per capita (constant 2010 US\$). Source: World Bank

Despite the slowdown in Chinese economic development since 2007, which has reduced the differential between China and the United States, from 7.45\% in the period 1992-2007 to 5.13\% in the last five years, everything seems indicate that the Chinese economy will continue showing greater growth, which will allow to reduce, at the end of the next 8 years (2017-2025), to $4.86 \%$ the annual growth differential with respect to the USA. The foregoing would mean that Chinese GDP per capita would pass from representing 13.80\% of the GDP pc of the United States in 2017, to exceed 20\% in 2025.

The adjustment of the prospective model (for the period 2005-2013) predicts an increase in the highly artificialized area of $133.55 \%$ between 2013 and 2025, going from 194,362 to 414,681 km². Figure 11 shows the evolution of Chinese UAs between 2013 (red) and 2025 (blue).

This increase in the land highly impacted by the urbanization will correspond, mainly, to the provinces with the lowest level of income. As shown in Figure 12, there is a negative correlation between the share of national GDP per capita (\%) in 2013 and the increase in artificialized land in the period 2013-2025. Provinces such as Guizhou (53\% share of GDP per capita in Mainland China), Shanxi $(80 \%)$, Hebei $(89 \%)$, Guangxi $(72 \%)$ or Xinjiang Uygur (60\%) have probably experienced the sharpest increases. In contrast Shanghai (208\%), Beijing (215\%), Guangdong (135\%), Jiangsu (172\%) or Tianjin (230\%), observe the lower relative shares of urbanization. 


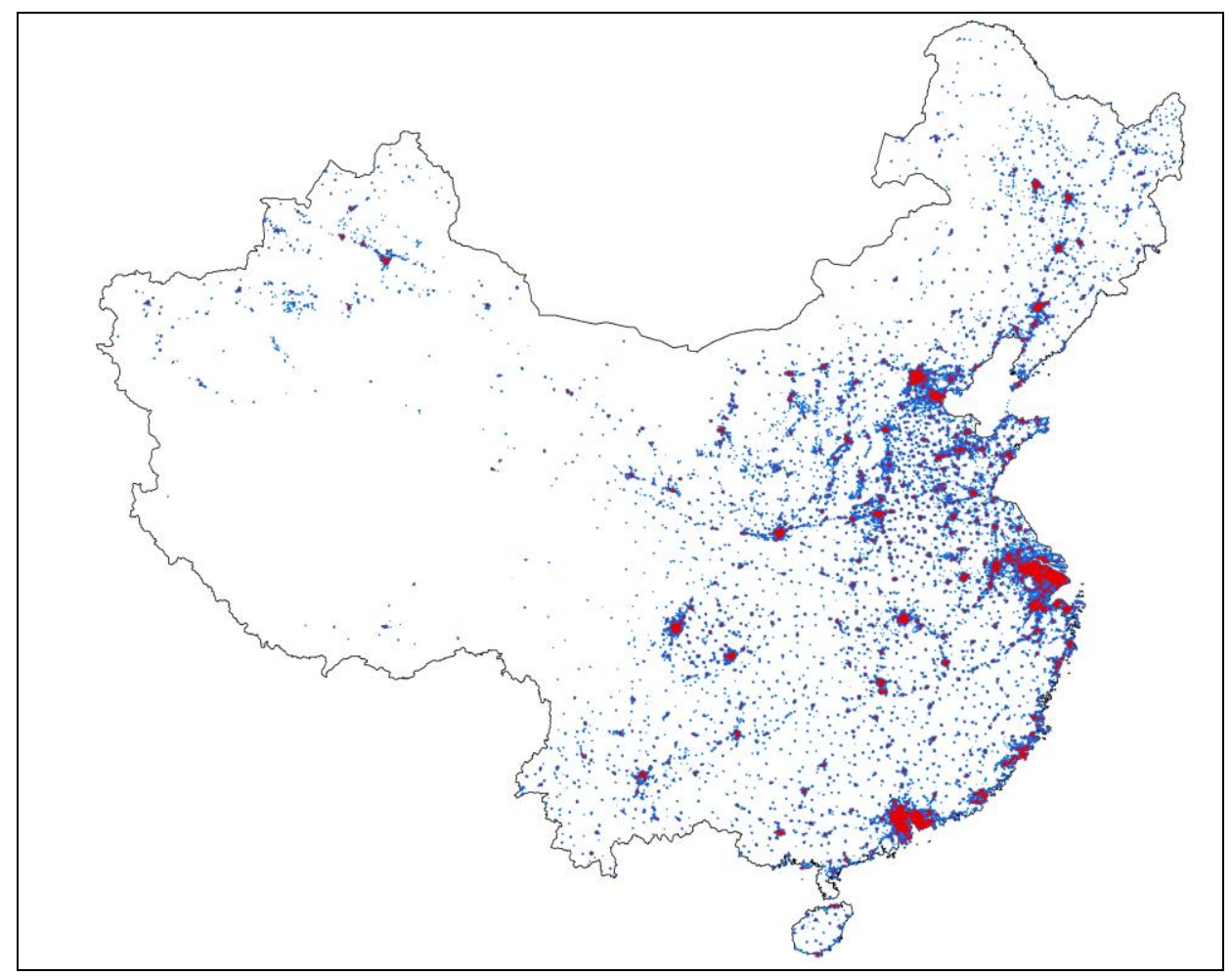

Figure 11. UAs 2013-2025

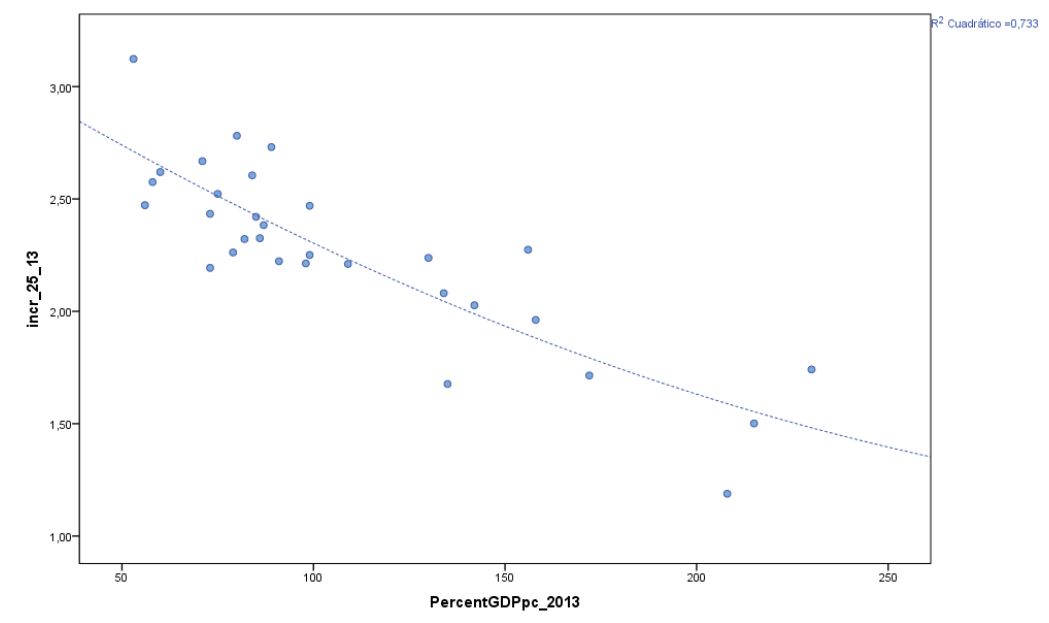

Figure 12. Increase in land highly impacted by light $(2013-2025)$ vs. \% GDP per capita (Mainland China $=100)$

Figure 13 shows how the relative increase of the urbanized surface moves towards the center and the west of China. The provinces in intense green color (Shanghai and Beijing) will probably have increases in the urbanized area below $60 \%$. Also in the east coast of China in green, the provinces with moderate increases, between 60 and 100\%. In yellow, the provinces with an increase in the UAs between 100 and 125\%. In orange, the provinces with increases between 125 and $150 \%$. And, finally, in red provinces with growths above $150 \%$.

The center of gravity (figure 13) of the urbanization will continue moving, slowly, towards the west. Also, the attractiveness generated by the great megalopolis of north-east China (Beijing-Tianjin) probably displaced the center slightly to the north. Hebei, surrounding Beijing, is among the provinces that will see the biggest growth between 2013 and 2025. On the other hand, Guangdong, in the South, probably will not have a great growth due to the absence of large urbanized areas in the vicinity of the great megalopolis of the Pearl River. 
Figure 14 shows the predicted increase (for the period 2013-2025) of the urbanized area in the three major Chinese megalopolis.

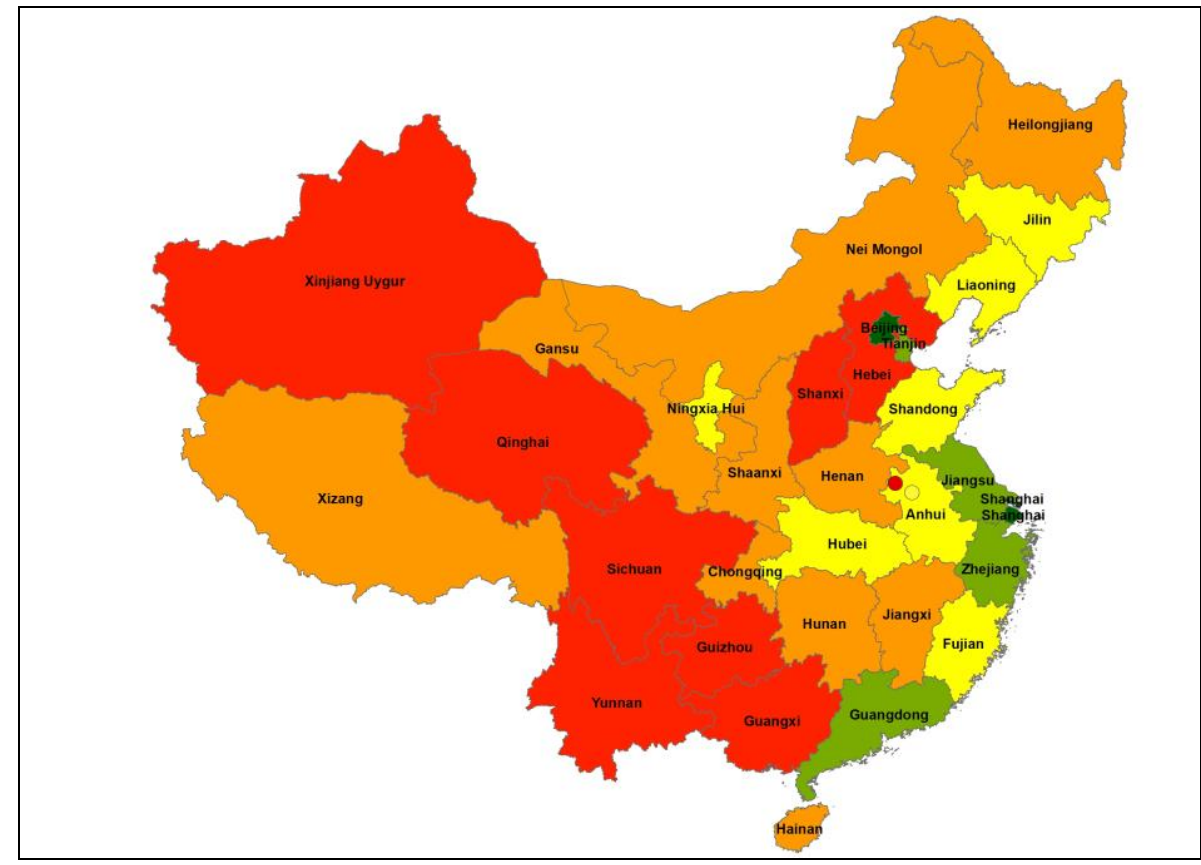

Figure 13. Relative increase of the urbanized land (2013-2025)

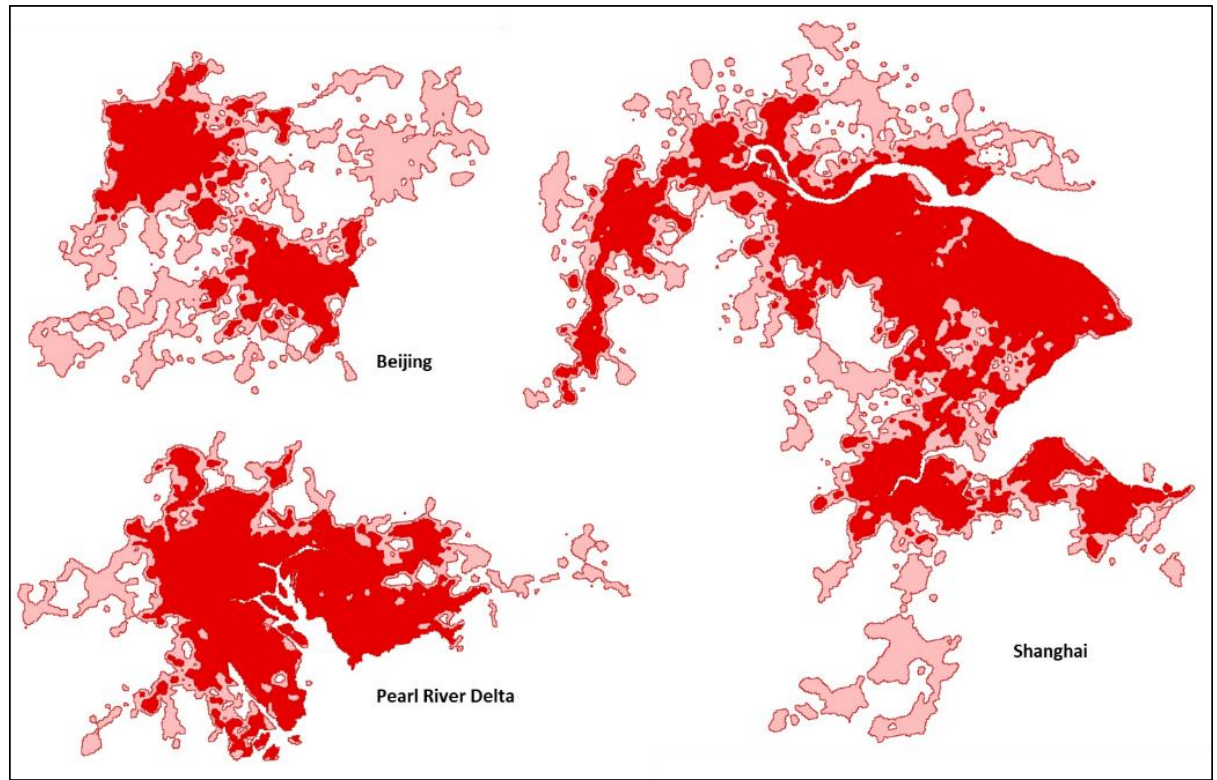

Figure 14. Megalopolis of Shanghai, Beijing-Tianjin and Pearl River Delta. 2013-2025

The prospective model predicts an important change of scale of the megalopolis of the capital of China (with an increase of the area impacted by nighttime light of $159.46 \%$ ), which will incorporate new cities and metropolitan areas in its vicinity (such as Tangshan), against a more moderate growth of Shanghai $(84.30 \%)$ and, above all, of the Pearl River Delta $(52.18 \%)^{14}$.

14 The urbanized surface growth indicated in the text refers to the urban areas of the three large Chinese megalopolis for 2013 and 2015. These megalopolis have been calculated, for each of those years, by a buffer of $2.5 \mathrm{~km}$ of the contour of intensity 37 (or higher). The surfaces of the UAs of 2013 do not incorporate that of the aggregated areas in 2025. The real growth of the urban areas of the three agglomerations is, therefore, lower than those described in the text. 


\section{CONCLUSIONS}

The research presented in this paper has attempted to determine the growth of Chinese urbanized areas between 1992 and 2013, as well as develop a prospective model to forecast growth between 2013 and 2025.

The results of the investigation make it possible to verify that despite the inherent difficulties of low resolution and lack of on-board calibration of the nighttime imagery of the DMSP-OLS, the data supplied from the night lights can be used to analyze the development of the urban areas. The integration of the Visible Infrared Imaging Radiometer Suite (VIIRS) data (the information of which starts in 2012) remains for further investigation.

This paper documents the "urban revolution" produced in China as a result of its extraordinary economic and social vitality experienced from the 90s. Between 1992 and 2013 the areas highly impacted by the nightlight have grown $802.95 \% ! !$

The research carried out also allows predicting the future urban development until 2025. The prospective model developed advances a growth of the Urban Areas in China of $113.35 \%$ between 2013 and 2025. A growth that will probably continue to consolidate the large agglomerations of the East coast of China. But that also seems to progressively redirect urban development to the center and west of the country.

\section{REFERENCES}

[1] Elvidge, C.D., Baugh, K.E., Anderson, S.J., Sutton, P.C. and Ghost, T., "The Night Light Development Index (NLDI): a spatially explicit measure of human development from satellite data", Social Geography, 7, 23-35 (2012).

[2] Florida, R., Gulden, T. and Mellander, C., "The rise of the mega-region", Cambridge Journal of Regions, Economy and Society, 1 (3), 459-476 (2008).

[3] Arellano, B. and Roca, J., "Las megaestructuras urbanas del siglo XXI: un ensayo para la identificación y caracterización de las megalópolis", ACE, Architecture, City and Environment, 9 (25), 127-158 (2014).

[4] Arellano, B. and Roca, J., "Defining urban and rural areas: a new approach," Proc. SPIE 10431, Remote Sensing Technologies and Applications in Urban Environments II, 104310E (2017); doi: 10.1117/12.2277902.

[5] Dou, X., Arellano, B. and Roca, J., "China's Interprovincial Population Floating Based on the Interaction Value Analysis Migratory system in China -Towards a bidirectional regional migration", Geographical Research, vol. 37, $\mathrm{n}$. 9, (2018).

[6] United Nations, [World's population increasingly urban with more than half living in urban areas], New York, United Nations publication, UN http://www.un.org/en/development/desa/news/population/world-urbanization-prospects2014.html (2014).

[7] Tsai, Y. H., "Quantifying Urban Form: Compactness versus 'Sprawl”, Urban Studies, 42(1), 141-161 (2005).

[8] United Nations, [World Urbanization Prospects: The 2001 Revision], United Nations publication, ESA/P/WP 173, New York (2002).

[9] Margalef, R., "Acelerada inversión de la topología de los sistemas epicontinentales humanizados", in Naredo, J.M., Gutiérrez, L., [La incidencia de la especie humana sobre la faz de la tierra (1955-2005)], Universidad de Granada/Fundación César Manrique, Granada, 217-219 (2005).

[10] Gu, C. and Pang, H., "Evolution of Chinese urbanization spaces: Kernel spatial approach", Scientia Geographical Sinica, 29 (1), 10-14 (2009).

[11]Fang, C. and Yu, D., [China's New Urbanization. Developmental Paths, Blueprints and Patterns], Springer Berlin Heidelberg (2016). 
[12] Fang, C., "Urbanization and urban development in China after the reform and opening-up", Economic Geography, 29(1), 19-25 (2009).

[13] United States Census Bureau, [2010 Census Urban and Rural Classification and Urban Area Criteria], https://www.census.gov/geo/reference/ua/urban-rural-2010.html (22 September, 2014).

[14] Bureau of the Census, "Proposed Urban Area Criteria for the 2010 Census", Federal Register, Typology 75, No. 163 / Tuesday, August 24, 2010 / Notices (2010).

[15] European Commission, [A harmonised definition of Cities and Rural Areas: The new Degree of Urbanisation], Working Paper 1/2014 (2014).

[16] Eurostat, European Commission, [Regional Year Book 2010], Luxembourg, Publications Office of the European Union (2010).

[17] Berry, B. J. L., [Urbanization and counterurbanization], Beverly Hills, California. Sage Publications (1976).

[18] Berg L. van den, Drewett, R, Klaasen, L. H., Rossi, A. and Vijverberg, C. H. T., [Urban Europe: a study of growth and decline], Elmsford, N.Y./Oxford, England, Pergamon Press, xxii, (1982).

[19] Bauer, G. and Roux, J. M., [La rurbanisation ou la ville éparpillée]. Paris, 1976. Éditions du Seuil (1976).

[20] Daniels, T., "What to do about rural sprawl?", American Planning Association Conference. Seattle, WA (1999).

[21] Theobald, D. M., "Landscape Patterns of Exurban Growth in the USA from 1980 to 2020", Ecology and Society, 10(1), 32. URL: http://www.ecologyandsociety.org/vol10/iss1/art32/ (2005).

[22] United Nations, [Urbanization and Development: Emerging Futures], World Cities Report, United Nations Human Settlements Programme (UN-Habitat) (2016).

[23] Chen 1, J., Cao, X., Peng, S. and Ren, H., "Analysis and Applications of GlobeLand30: A Review”, Int. J. Geo-Inf. 2017, 6, 230; doi:10.3390/ijgi6080230 (2017).

[24] Short Gianotti, A.G., Getson, J.M., Hutyra1, L.R. and Kittredge, D.B., "Defining urban, suburban, and rural: a method to link perceptual definitions with geospatial measures of urbanization in central and eastern Massachusetts", Urban Ecosyst 2016-19, 823-833 (2016).

[25] Theobald D.M., "Placing exurban land-use change in a human modification framework", Ecol Environ 2(3), 139-144 (2004).

[26] Ridd, M. K., "Exploring a V-I-S (vegetation - impervious surface - soil) model for urban ecosystem analysis trough remote sensing: comparative anatomy for cities", International Journal of Remote Sensing, 16- 12, 2165-2185 (1995).

[27] He, C., Shi, P., Li, J., Chen, J., Pan, Y., Li, J., et al., "Restoring urbanization process in China in the 1990 by using non-radiance calibrated DMSP/OLS nighttime light imagery and statistical data", Chinese Sci Bull, 51(13), 16141620 (2006).

[28]NASA Earth Observatory, "Night Lights 2012 - The Black Marble", http://earthobservatory.nasa.gov/NaturalHazards/view.php?id=79803 (30 October, 2013).

[29] Elvidge, C.D., Baugh, K., Zhizhin, M. and Hsu, F. C., 2013, "Why VIIRS data are superior to DMSP for mapping night-time lights", Proceedings of the Asia-Pacific Advanced Network, 35, 62-69, 2013.

[30] Liu, Z., He, C., Zhang, Q., Huang, Q. and Yang, Y., "Extracting the dynamics of urban expansion in China using DMSP-OLS nighttime light data from 1992 to 2008", Landscape and Urban Planning 106, 62- 72 (2012).

[31] Elvidge, C. D., Hsu, F., Baugh, K. E. and Ghosh, T., "National Trends in Satellite-Observed Lighting: 1992-2012", in Weng, Q., [Global Urban Monitoring and Assessment through Earth Observation], CRC Press (2014). 